\title{
Image Segmentation Based on New Modification on Normalized-Cut Algorithm
}

\author{
Khalil I. Alsaif \\ College of Computer Sciences and Mathematics \\ University of Mosul
}

Received on:26/8/2010

Accepted on:10/11/2010

\begin{abstract}
In this research, Normalized Cut algorithm was studied to segments any type of digital images which was widely used recently. In this paper wavelet transformation, and high-high frequency components which hold the edges of the image will be used to replace classical high frequency filters of the old techniques achieved by the normalized cut algorithm ( which used CANNY filter for edge detection).

When the new modification of the proposed algorithm applied on the different type of digital images (medical, aerial and natural images) after crossover the CANNY filter by the wavelet high-high coefficients, a very efficient segments were found much better than the segments got before, in addition to a deep information can be seen if the selected segment is projected on the original image to be recognized.
\end{abstract}

Keywords: Image segmentation, Normalized Cut algorithm, wavelet transformation, CANNY filter.

$$
\begin{gathered}
\text { تقيع الصورة بالاعتماد على تحوير جديد على خوارزمية القطع السوية إبراهيم السيف علوم الحاسوب والرياضيات } \\
\text { جامعة الموصل }
\end{gathered}
$$

تاريخ القبول: 2010/11/10

تاريخ الاستلام: 2010/8/26

الملخص

في هذا البحث, تم دراسة خوارزمية القطع السوي ألمعتمده في تقطيع كافة أنواع الصور ألرقميه

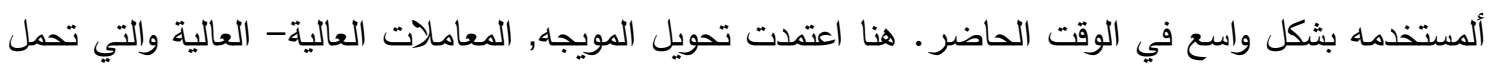

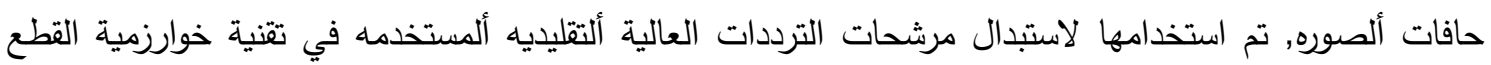
السوي الكلاسيكية (التي تعتمد مرشح كاني لاكتشاف الحافات).

عند تطبيق التحوير الجديد للخوارزمية ألمقترحه على أنواع مختلفة لصور رقميه (طبية, فضائية و طبيعية) يعد استبدال مرشح كاني بالمعاملات العالية- العالية لتحويل المويجه, تم الحصول على مقاطع ذات كفائه عالية أفضل بكثير من المقاطع التي تم الحصول عليها سابقا, بالإضافة إلى معلومات عميقة يمكن مشاهدتها إذا لئا تم إسقاط المقطع المنتخب على اصل ألصوره المطلوب تمييزها. 


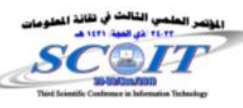

الكلمات المفتاحية: تقطيع الصورة، خوارزمية القطع السوي، تحويل المويجة، مرشح كاني.

\section{Introduction:}

Segmentation is one of the most important techniques for image processing ${ }^{[1]}$. The purpose of segmentation is to partition an image into distinct, semantically meaningful entities by defining boundaries between features and objects in an image based on some constraint, or homogeneity predicate. Specifically, the segmentation problem is defined as sufficiently partitioning an image into non-overlapping regions ${ }^{[2]}$.. Segmentation can therefore be formally defined as follows:

If $\mathrm{F}$ is the set of all pixels and $\mathrm{P}(\mathrm{)})$ is a homogeneity predicate defined on groups of connected pixels, then segmentation is a partitioning of the set $\mathrm{F}$ into a set of connected subsets or regions $(\mathrm{S} 1, \mathrm{~S} 2, \ldots, \mathrm{Sn})$ such that:

$$
\bigcup_{i=1}^{n} S_{i}=F \text { with } S_{i} \mathrm{I} \quad S_{j}=\varnothing, \quad i \neq j
$$

The homogeneity predicate $\mathrm{P}(\mathrm{Si})=$ true for all regions $(\mathrm{Si})$ and $\mathrm{P}(\mathrm{Si} \square \mathrm{Sj})=$ false , when $\mathrm{Si}$ is adjacent to $\mathrm{Sj}{ }^{[3]}$.

Homogeneity predicates are usually based on image intensity, color, texture, etc. According to Harlick and Shapiro ${ }^{[4]}$, image segmentation can be classified into the following categories:

\section{i) Spatial Clustering}

Haralick and Shapiro ${ }^{[4]}$ present that the difference between clustering and segmentation is that in image segmentation, grouping is done in the spatial domain of the image, while clustering is done in measurement space. It is also possible for clustering to result in overlapping regions, while that is not the case for segmentation results. Clustering and spatial segmentation can be combined to form spatial clustering, which combine histogram techniques with spatial linkage techniques for better results.

\section{ii) Split and Merge Segmentation}

Regions in an image are a group of connected pixels with similar properties ${ }^{[5]}$. The split method begins with the entire image, and repeatedly splits each segment into quarters if the homogeneity criterion is not satisfied. These splits can sometimes divide portions of one object. The merge method joins adjacent segments of the same object.

In intensity based segmentation, the boundaries that separate regions may need to be redefined due to under- or over-segmentation of regions. Split and merge segmentation can also handle this task. Under-segmented regions are corrected by adding boundaries to, or splitting, certain regions that contain parts of different objects. Over segmented regions are corrected by eliminating false boundaries and merging adjacent regions if they belong to the same object or feature.

\section{iii) Region Growing}

Region growing has shown to be a very useful and efficient segmentation technique in image processing ${ }^{[5,6]}$. Region growing in its simplest sense is the process of joining neighboring points into larger regions ${ }^{[7]}$ based on some condition or selection of a threshold value. Seeded region growing starts with one or more seed points and then grows the region to form a larger region satisfying some homogeneity constraint. The homogeneity of a region can be dependent upon any characteristic of the region in the 
image: texture, color or average intensity. One specific approach to region growing is described in the next section.

\section{Fundamentals of Wavelet Transform ${ }^{[8]}$ :}

Wavelet transforms (WT) provide the alternative to the Short-Time Fourier transform (STFT) for non-stationary signal analysis ${ }^{[\mathbf{9 , 1 0}}$. Both STFT and WT result in signal decomposition into two-dimensional function of time and frequency respectively scale. The basic difference between these two transforms is in the construction of the window function which has a constant length in the case of the STFT (including rectangular, Blackman and other window functions) while in the case of the WT wide windows are applied for low frequencies and short windows for high frequencies to ensure constant time-frequency resolution. Local and global signal analysis can be combined in this way. Wavelet functions used for signal analysis are derived from the initial basic (mother) function $\mathrm{h}(\mathrm{t})$ forming the set of functions

$$
h_{m, k}(t)=\frac{1}{\sqrt{a}} h\left(\frac{1}{a}(t-b)\right)=\frac{1}{\sqrt{2^{m}}} h\left(2^{m} t-k\right)
$$

for discrete parameters of dilation $a=2 \mathrm{~m}$ and translation $\mathrm{b}=\mathrm{k} 2 \mathrm{~m}$. Wavelet dilation corresponds to spectrum compression according to Fig(1). The most common choice includes Daubechies wavelets even though their frequency characteristics stand for approximation of band-pass filters only. On the other hand harmonic wavelets introduced in $^{[11]}$ can have broader application in many engineering problems owing to their very attractive spectral properties.

Shannon Wavelet Function

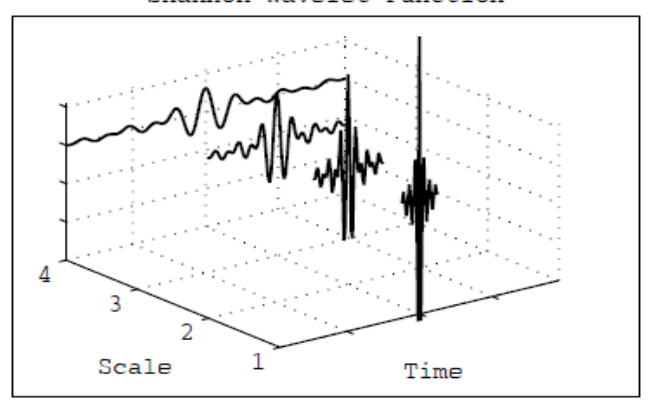

Spectrum Estimation

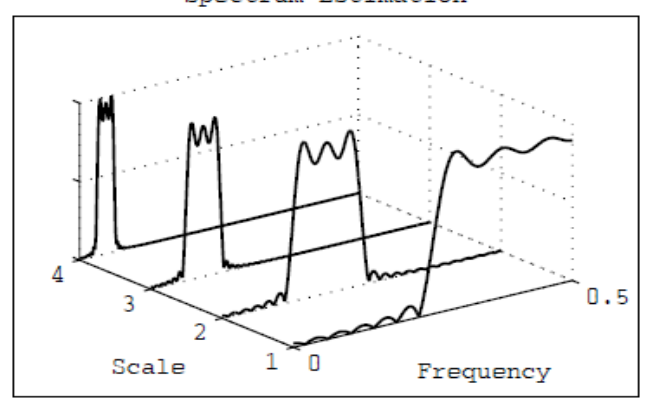

Figure (1) Spectral analysis of selected wavelet function presenting relation between time dilation and the corresponding spectrum compression

\section{Normalized Cuts and Image Segmentation:}

Jianbo Shi and Jitendra Malik in their paper published at $2000^{[12]}$ propose a novel approach for solving the perceptual grouping problem in vision. Rather than focusing on local features and their consistencies in the image data, their approach aims at extracting the global impression of an image. they treat image segmentation as a graph partitioning problem and propose a novel global criterion, the normalized cut, for segmenting the graph. The normalized cut criterion measures both the total dissimilarity between the different groups as well as the total similarity within the groups.

They show that an efficient computational technique based on a generalized eigen value problem can be used to optimize this criterion. They have applied that approach to segmenting static images, as well as motion sequences, and found the results to be very encouraging. 
Jianbo Shi and Jitendra Malik grouping algorithm consists of the following steps:

1. Given a set of features, set up a weighted graph $\mathrm{G}(\mathrm{V}, \mathrm{E})$, compute the weight on each edge (they use normally CANNY filter for edge detection), and summarize the information into $\mathrm{W}$ and $\mathrm{D}$.

2. Solve $y(D-W) x$. for eigenvectors with the smallest eigenvalues.

3. Use the eigenvector with the second smallest eigenvalue to bipartition the graph by finding the splitting point such that Ncut is minimized.

4. Decide if the current partition should be subdivided by checking the stability of the cut, and make sure Ncut is below the prespecified value.

5. Recursively repartition the segmented parts if necessary.

The number of groups segmented by this method is controlled directly by the maximum allowed Ncut.

The above modified by replacing the CANNY filter with WAVELET high frequencies coefficients(which called modified N-CUT)

\section{Applied examples on classical n-cut and the modified done on N-CUT :}

a) classical algorithm:

selecting medical images (kidney image) to be segmented into 64 segments then choosing special part to compaire it with the modified one.

b) Modified N-Cut algorithm: fig(5), fig(6) and fig(7) show the same sequence for the same Kidney image.

In the appendix other example (using aerial images) can be seen using both classical and modified one.
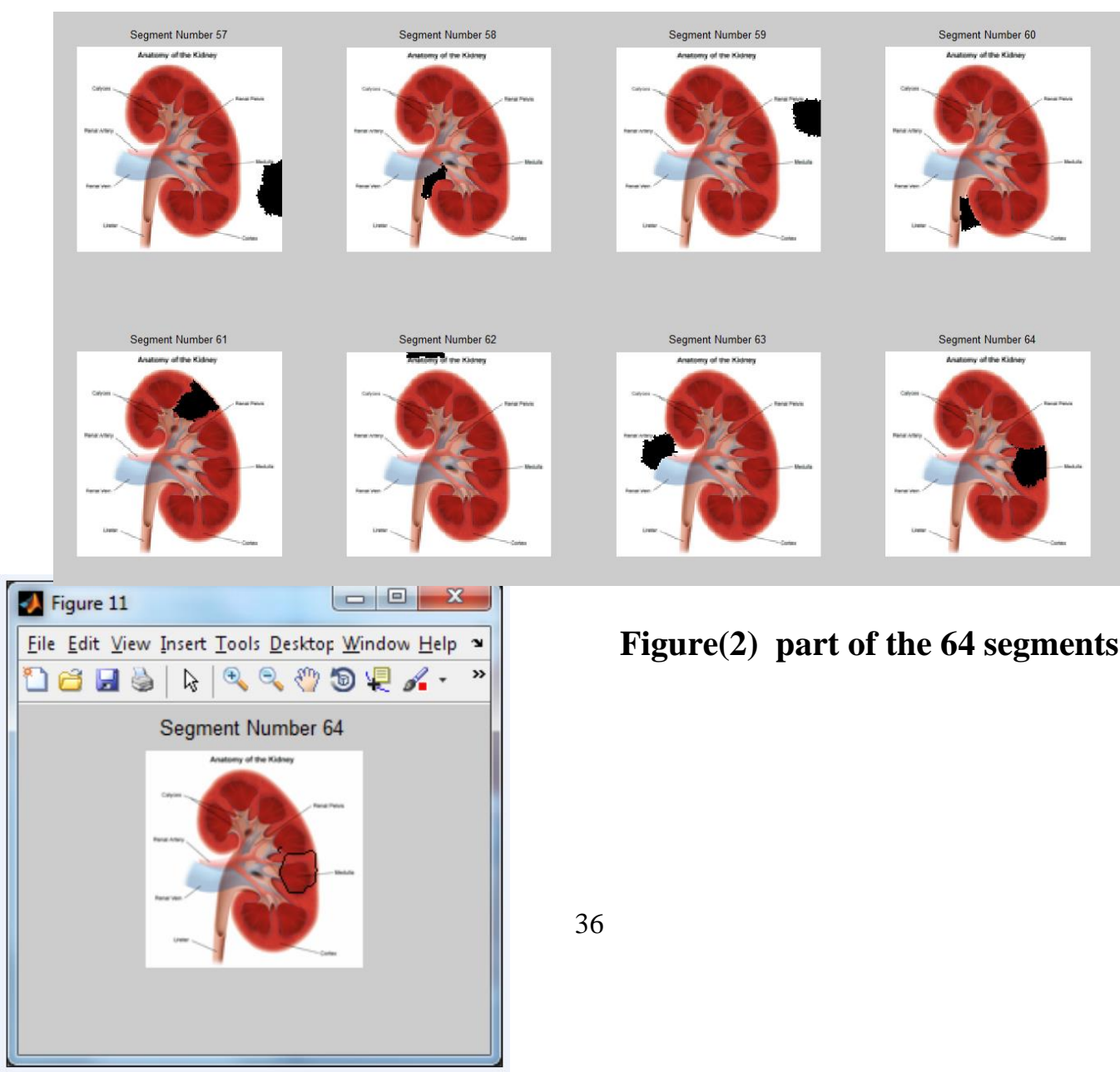

Figure(2) part of the 64 segments 


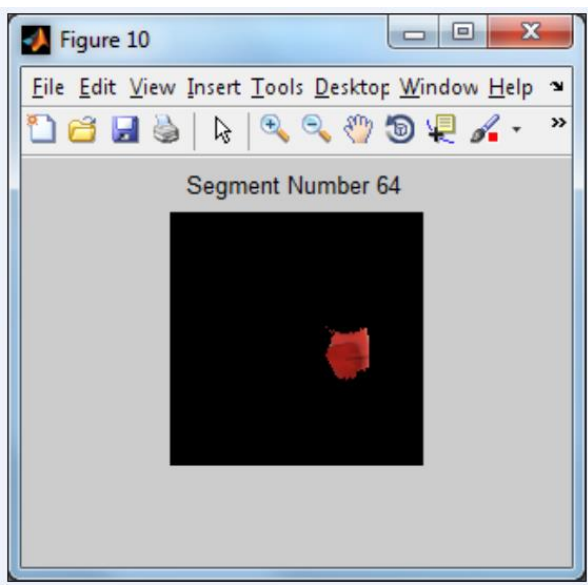

image of segment
Figure (4) detection of the selected part

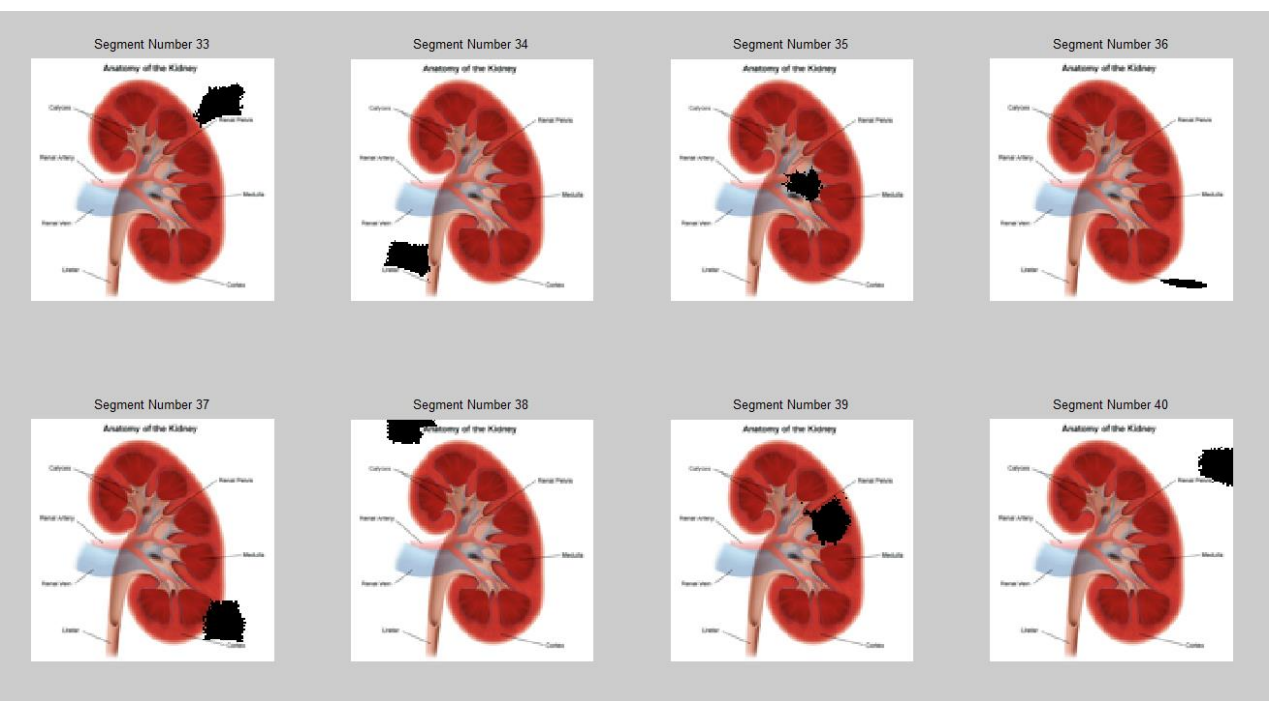

Figure (5)

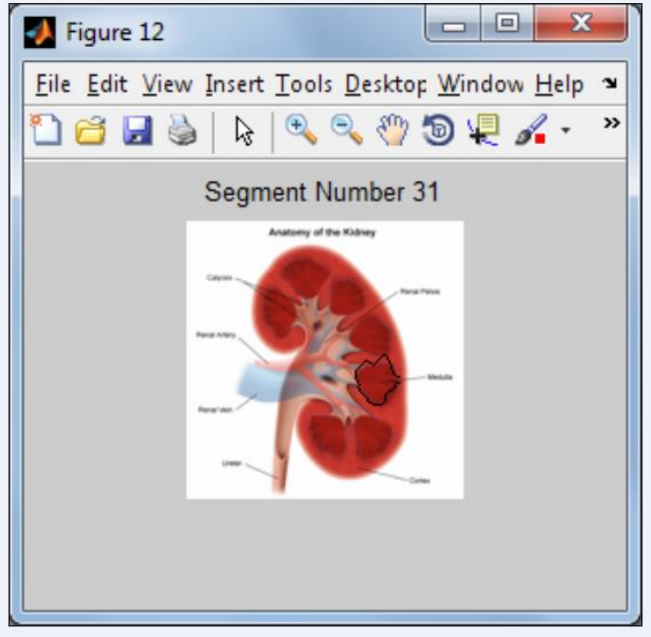

Figure (6) edge detection of the selected part

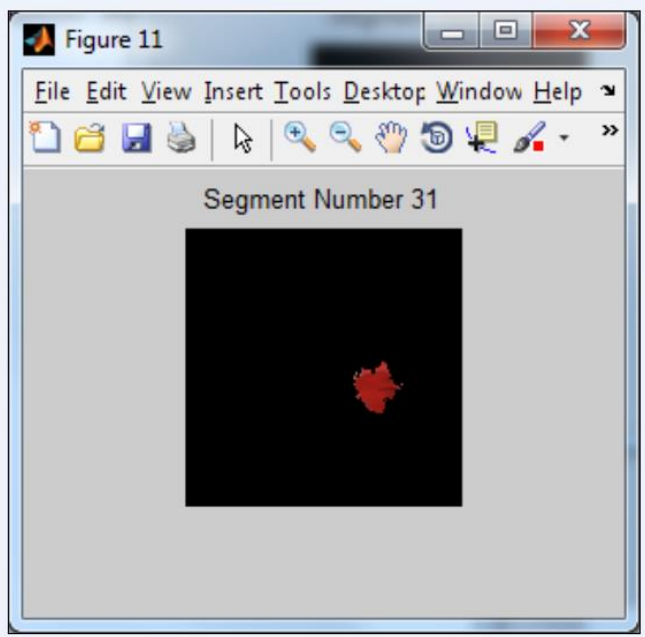

Figure (7) the image of the selected segment. 


\section{Discussion and Conclusion:}

Comparing the images of the edge detection for the same region in the kidney image you can see that replacing Canny filter for edge detection by the wavelet highhigh components may go in deep for the details that hold in that region. Expanding the selected region give more details that will be helpful to study.

So many examples applied on both techniques, using different types of images, all of them gave sharp edge which used to segment special region inside the image.

\section{$\underline{\text { REFERENCE }}$}

[1]. Sonka, M., Hlavac, V., and Boyle, R., "Image Processing, Analysis, and Machine Vision”, Brooks/Cole Publi shing Company, 1998.

[2]. Medical image segmentation by felicia s. jones b.a., depauw university, 2001 a thesis submitted to the graduate faculty of the university of georgia in partial fulfillment of the requirements for the degree master of science athens, georgia

[3]. Pal, N., and Pal, S., “A Review on Image Segmentation Techniques", Pattern Recognition, 1993, 26, pp. 1277-1294

[4]. Haralick, R.M., and Shapiro, L.G. "SURVEY: image segmentation techniques", Computer Vision Graphics Image Processing, 1985, 29, pp. 100-132

[5]. Jain R. et al, Machine Vision, McGraw-Hill, Inc. 1995.

[6]. Gonzales, R.C. and Richard E. woods (2002). "Digital Image Processing", by Prentice-Hall,Inc. 2nd edition, pp. 567-635.

[7]. Zucker, S. W., "Region growing: Childhood and adolescence", Computer Graphics and Image Processing, 1976, 5, 382-399

[8]. J. Ptáček, A. Procházka, Wavelet Use for Image Restoration, In Proceedings of the Carpatian Control Conference, Zakopane, Poland, 2004

[9]. Kingsbury N., Magery J.: Wavelet Transforms in Image Processing. In Signal Analysis and Prediction, ECSAP-97, European Assoc. for Signal Processing, 1997.

[10]. Strang G., Nguyen T.: Wavelets and Filter Banks. Wellesley-Cambridge Press, 1996.

[11]. Newland D.E.: An Introduction to Random Vibrations, Spectral and Wavelet Analysis. Longman Scientific \& Technical, 3e, Essex, U.K., 1994.

[12]. IEEE TRANSACTIONS ON PATTERN ANALYSIS AND MACHINE INTELLIGENCE, VOL. 22, NO. 8, AUGUST 2000 


\section{Appendix}
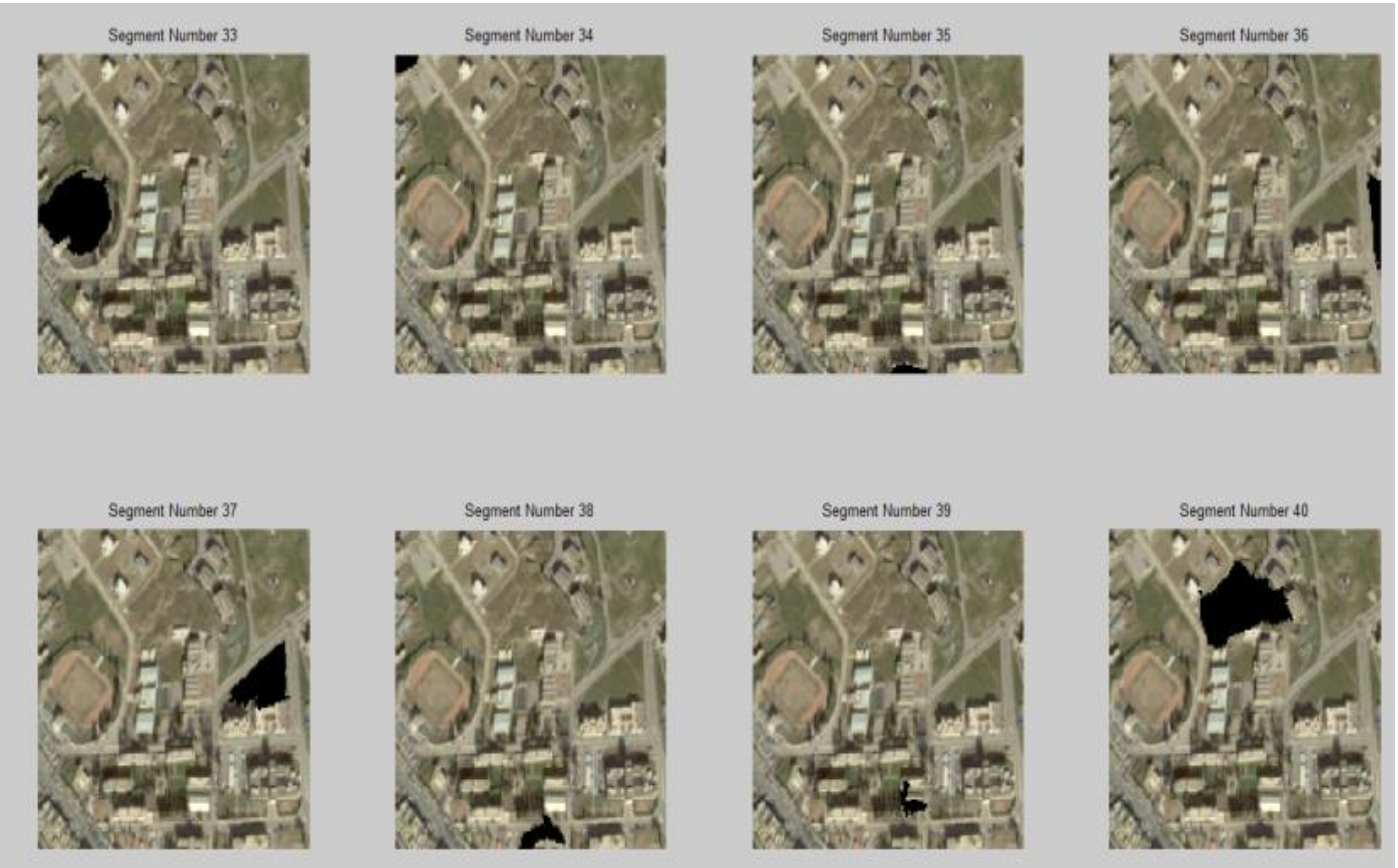

Figure(a-1)
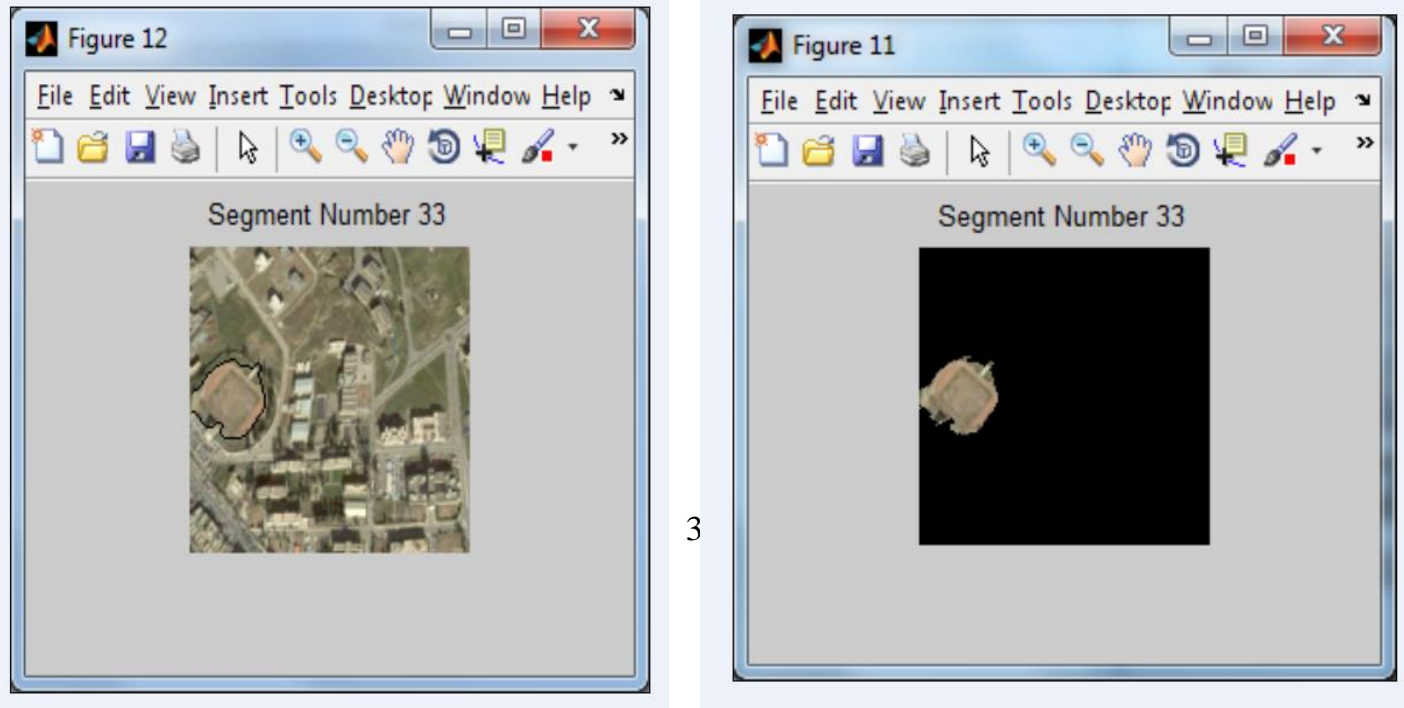
Figure(a-2)
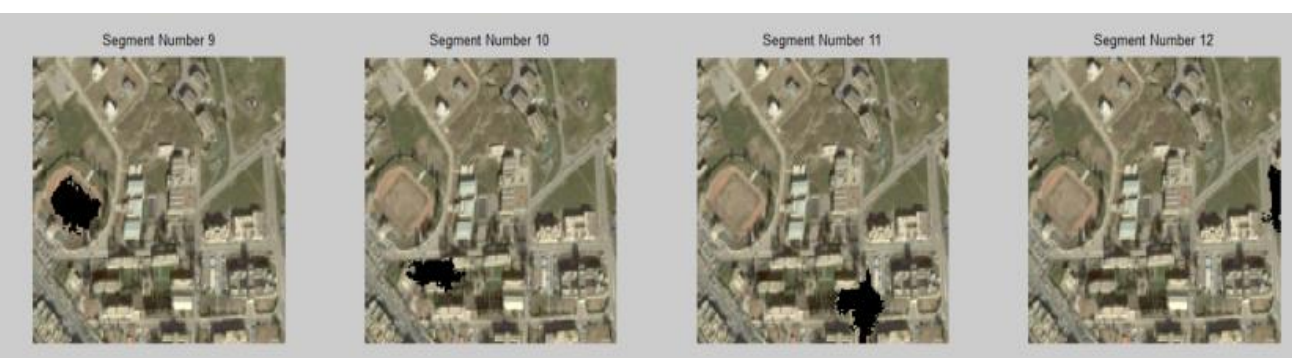

Segment Number 13

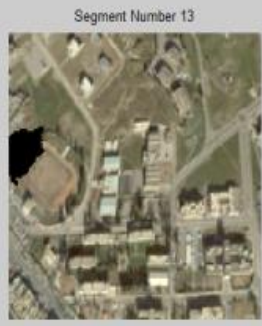

Segment Number 14

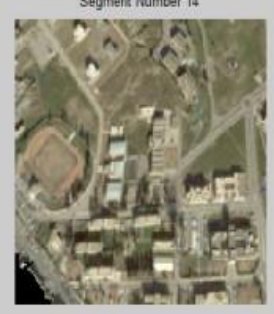

Figure(a-3)

Figure(a-4)

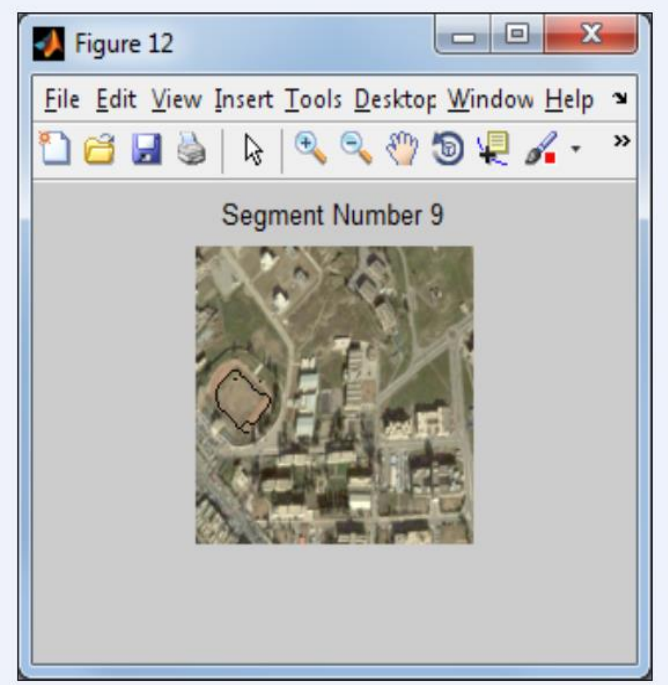

Figure(a-5)

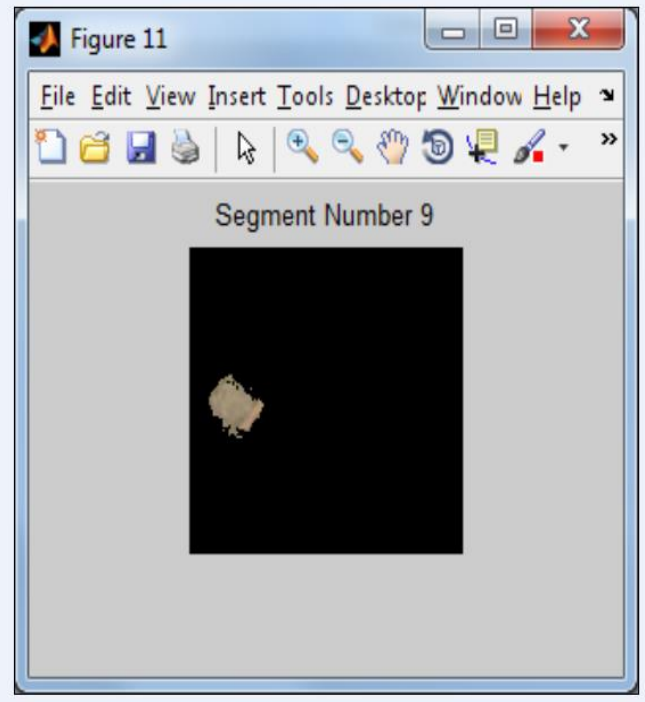

Figure(a-6) 
